ISSN 1518-3483

Licenciado sob uma Licença Creative Commons

\title{
Reflexões de professores participantes em um Curso de Pedagogia Universitária
}

\author{
Reflections of participants teachers in an University \\ Pedagogy Course
}

\author{
Adriana Katia Corrêa, Alma Blasida Concepcion Eliazur Benitez Catirse, \\ Edson Garcia Soares, Glaucia Maria da Silva, Maria Conceição Bernardo de \\ Mello e Souza, Marlene Fagundes Carvalho Gonçalves, \\ Noeli Prestes Padilha Rivas, Yassuko lamamoto*
}

Universidade de São Paulo (USP), Ribeirão Preto, SP, Brasil

\section{Resumo}

Este artigo analisa a formação de professores universitários, no contexto da pesquisa Curso Pedagogia Universitária: os professores e sua prática pedagógica desenvolvida pelo Grupo de Apoio Pedagógico do Campus USP-Ribeirão Preto/Universidade de São Paulo - Brasil - (GAPRP). Trata de pesquisa descritivo-exploratória, de natureza qualitativa que se propõe a analisar as reflexões de professores, participantes do I e II Curso de Pedagogia Universitária realizado em Ribeirão Preto em 2008 e 2009, acerca de sua prática

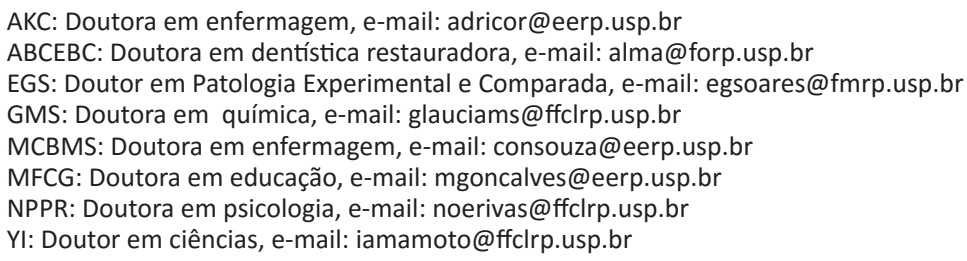

AKC: Doutora em enfermagem, e-mail: adricor@eerp.usp.br ABCEBC: Doutora em dentística restauradora, e-mail: alma@forp.usp.br EGS: Doutor em Patologia Experimental e Comparada, e-mail: egsoares@fmrp.usp.br GMS: Doutora em química, e-mail: glauciams@ffclrp.usp.br MCBMS: Doutora em enfermagem, e-mail: consouza@eerp.usp.br MFCG: Doutora em educação, e-mail: mgoncalves@eerp.usp.br NPPR: Doutora em psicologia, e-mail: noerivas@ffclrp.usp.br YI: Doutor em ciências, e-mail: iamamoto@ffclrp.usp.br 
pedagógica. Os dados revelam que as reflexões desses professores contemplam a revisitação de suas práticas pedagógicas, os limites contextuais e administrativos e a gestão do projeto político pedagógico com possibilidades de mudanças. Evidenciam-se também alguns pontos de tensão que necessitam ser trabalhados: aprendizagem da docência como perspectiva individual versus docência como perspectiva coletiva; formação pedagógica como prática sócio-política versus prática instrumental e valorização da pesquisa em detrimento do ensino.

Palavras-chave: Ensino Superior. Pedagogia Universitária. Práticas Pedagógicas.

\begin{abstract}
This article analyzes the university teachers formation in the context of the research University Pedagogy Course: teachers and their pedagogical practice, developed by the Pedagogical Support Group of the University of São Paulo campus situated in the city of Ribeirão Preto, State of São Paulo, Brazil. It is a descriptive-exploratory qualitative research that aims to analyze the reflections of teachers, participants of the University Pedagogy Course held in the city of Ribeirão Preto in 2008 and 2009, about their pedagogical practice. The data revealed that the reflections made by these teachers include revisitation of pedagogical practices, contextual and administrative ambits and management of the pedagogical project with the possibility of changes in teaching practice. Some tension points must be addressed: teaching learning as individual perspective versus teaching as collective perspective; teacher training as socio-political practice versus instrumental practice and valuation of research at the expense of teaching.
\end{abstract}

Keywords: Higher Education. University Pedagogy. Pedagogical practices. 


\section{Introdução}

As mudanças no campo social e econômico têm transformado profundamente o trabalho dos professores universitários (SGUISSARDI, 2004, 2009; CHAUÍ, 2003). Nas últimas décadas, fenômenos como a inclusão social, a revolução tecnológica, mudanças no mundo do trabalho, entre outras, têm trazido demandas importantes para a universidade, envolvendo a atuação e a formação dos professores. No entanto, o docente universitário é profissional de um campo específico do conhecimento, com frágil formação pedagógica e que se dedica, além da docência, à pesquisa e extensão (PIMENTA; ANASTASIOU, 2011; CUNHA; BROLIO, 2012; ZABALZA; CERDEIRIÑA, 2012; ZABALZA, 2007).

No Brasil, não há diretrizes nacionais para a formação do professor universitário. A Lei de Diretrizes e Bases da Educação Nacional (BRASIL, 1996) indica que o professor universitário deverá ser preparado para o exercício do Magistério Superior nos cursos de pós-graduação, prioritariamente, em nível de Mestrado e Doutorado. Nesses programas, a preparação profissional voltada para as atividades de pesquisa e de produção do conhecimento específico, bem como a socialização dessa produção, conferem visibilidade e status ao pesquisador (ALMEIDA; PIMENTA, 2011). Os cursos de pós-graduação, em sua maioria, não valorizam a formação pedagógica do docente universitário (CUNHA; BROLIO, 2012).

Segundo Zabalza (2007), não basta o domínio dos conteúdos, nem ser um bom pesquisador para que o aluno aprenda efetivamente, constituindo-se num profissional mais culto, crítico e comprometido socialmente. Há necessidade da formação pedagógica, que fundamenta esse saber. Tal compreensão motivou o desenvolvimento de um campo de saber denominado pedagogia universitária, entendido como "o conjunto de concepções de natureza pedagógica, psicológica, filosófica, política, ética e epistemológica que articulam a prática educativa e sustentam as conexões entre universidade e sociedade" (ALMEIDA, 2012, p. 96). Nesse contexto, algumas Instituições de Educação Superior têm desenvolvido 
experiências de formação pedagógica (ALMEIDA, 2012; CUNHA, 2014; VEIGA, 2012).

Na Universidade de São Paulo (USP) os Cursos de Pedagogia Universitária (PU), promovidos pela Pró-Reitoria de Graduação para os docentes dos Campi da USP (capital e interior) vêm sendo desenvolvidos como um programa de formação continuada, ministrados aos docentes interessados, desde 2007, em parceria com a Comissão de Apoio Pedagógico (CAP) e os Grupos de Apoio Pedagógico (GAPs), criados institucionalmente nas distintas Unidades. Tais cursos têm como objetivo:

[...] estimular o desenvolvimento de intervenções no cotidiano visando efetivar o papel da pedagogia no ensino superior e compreender, renovar e valorizar o seu lugar nas práticas de coordenação pedagógica e de atuação docente nos contextos institucionais, a partir de diagnóstico efetivado com os grupos de trabalho (ALMEIDA, 2012, p. 123-124).

No campus da USP, em Ribeirão Preto, docentes oriundos de diversos cursos constituíram, em 2002, um grupo com o objetivo de "potencializar e articular mudanças mais efetivas nas práticas pedagógicas dos professores" (CORRÊA et al, 2011, p.77). Oficializado em 2004, o Grupo de Apoio Pedagógico do Campus USP Ribeirão Preto (GAPRP) vem configurando-se como espaço no qual se articulam, no âmbito da formação pedagógica, anseios e projetos individuais e coletivos de docentes, com políticas educacionais internas e externas à Universidade, por meio de assessorias, coordenação e atuação em cursos na área dos saberes pedagógicos para os docentes dos campi do interior do Estado, assim como o desenvolvimento de pesquisas em docência universitária.

Neste texto são apresentados resultados da pesquisa Curso Pedagogia Universitária: os professores e sua prática pedagógica desenvolvida pelo GAPRP, cujo objetivo foi analisar as reflexões acerca da prática pedagógica, elaboradas pelos professores participantes do I e II Cursos Pedagogia Universitária do Campus de Ribeirão Preto, em 2008 e 2009, considerando suas experiências e os conhecimentos aos quais vêm se 
aproximando no decorrer desse processo formativo. As questões que nortearam esta pesquisa: Quais concepções e experiências vêm marcando a prática pedagógica desses docentes inseridos em processo formativo institucionalizado? Quais as implicações que essa inserção poderá gerar para sua prática docente, a partir de suas próprias reflexões?

\section{Desenvolvimento profissional docente}

A docência universitária passa por constantes transformações nos seus fundamentos teórico-metodológicos, gerados a partir de estudos sobre o desenvolvimento profissional docente e, de modo específico, sobre um dos seus componentes, ou seja, a formação pedagógica do professor universitário.

Para analisar a formação pedagógica do professor universitário parte-se do pressuposto que o desenvolvimento é um processo complexo e multidimensional que abrange as necessidades pessoais, profissionais e organizativas, implicando na interação com os contextos espacial e temporal (VAILLANT; MARCELO, 2012). A formação pedagógica pode ser considerada como elemento fundante no processo de profissionalização docente ao lado da formação profissional e condições de trabalho. Pressupõe a compreensão do professor sobre si mesmo, seu desenvolvimento cognitivo, os princípios de ensino, do currículo, do estudante, dos meios e recursos didáticos, da aprendizagem e do contexto, envolvendo a aquisição de destrezas capacitadoras para a tarefa de ensinar (MARCELO GARCIA, 2009).

Há que se considerar também, como dimensões do trabalho docente, equilíbrio entre teoria e prática que orienta projetos formativos, formação continuada no âmbito do trabalho, prática contextualizada do conhecimento, aportes teóricos sobre a prática e revisão do pensamento sobre a formação e experiência. A formação pedagógica do professor universitário pode estimular inovação, sentido crítico, criatividade, saberes, pesquisas, formas de institucionalização, organização e condições 
estruturais de operacionalização. Assim sendo, o desenvolvimento profissional docente consubstancia-se no coletivo, na profissionalização docente, na construção dos saberes mediante uma prática social, histórica e contextualizada (ALMEIDA; PIMENTA, 2011; PIMENTA; ANASTASIOU, 2011; MARCELO GARCIA, 2009).

Desenvolvimento profissional, identidade docente e revisitação de práticas pedagógicas estão inter-relacionadas. Segundo Nóvoa (2009), o processo identitário dos professores e a profissionalidade docente são construídas a partir da pessoalidade do professor. Nesse âmbito, o processo de revisitação das práticas pedagógicas pelos docentes enseja desejos e iniciativas em construir algo novo, tal como o debruçar-se sobre a docência orientada para a aprendizagem no qual o estudante passa a ser considerado um aprendiz, tendo em vista que essa "condição constitui o eixo central das atividades formativas da universidade" (ZABALZA, 2007, p. 181). Há ainda os limites contextuais e administrativos que dizem respeito à docência e à gestão do projeto pedagógico (construção, execução e avaliação), os quais demandam uma particular atenção ao desenvolvimento dos professores como inovadores e pesquisadores de sua própria ação pedagógica (VEIGA, 2008).

É preciso ainda situar a importância da relação do professor/estudante com o saber (CHARLOT, 2002). Nesta relação o papel do professor será o de desafiar, estimular os estudantes na relação com o objeto de aprendizagem, auxiliando-os na tomada de consciência das necessidades apresentadas socialmente a uma formação universitária.

\section{Delineando trajetórias}

Esta pesquisa descritivo-exploratória, de natureza qualitativa, propõe-se a analisar as reflexões dos professores sobre a sua ação docente no cotidiano acadêmico, considerando os conhecimentos trabalhados nos Cursos de Pedagogia Universitária. As temáticas contemplaram a contextualização do Ensino Superior no Brasil, identidade docente, gestão de 
cursos, projeto político-pedagógico, processo de ensino-aprendizagem, metodologia e avaliação. A gestão dos Cursos de PU foi realizada por docentes membros do GAPRP que desenvolveram a presente pesquisa.

O corpus deste estudo constituiu-se de textos denominados reflexão sobre a prática pedagógica docente, uma das atividades realizadas pelos docentes participantes do I e II Cursos de Pedagogia Universitária, oferecidos em Ribeirão Preto para professores das áreas de exatas, humanas e biológicas dos campi de Ribeirão Preto, Bauru, São Carlos e Pirassununga, em 2008 e 2009. Os textos, solicitados aos docentes pela professora ministrante, tinham como objetivo estabelecer articulações entre sua prática pedagógica e as concepções teóricas do campo da pedagogia e da didática. As concepções, reflexões e narrativas acerca das experiências dos docentes participantes constituiu-se em material de análise, contribuindo para a construção de saberes relativos à pedagogia universitária.

Em 2008, participaram 72 docentes no I Curso de PU e, em 2009, 73 no II Curso de PU. Os textos reflexivos foram entregues por $18 \mathrm{e}$ 19 professores, respectivamente, totalizando 37 participantes. Cabe ressaltar que o número reduzido de textos reflexivos entregues pode estar relacionado com a sobrecarga de atividades no contexto de trabalho do docente universitário.

O perfil dos participantes desta pesquisa indicou a presença de 28 docentes da área da saúde, 05 das ciências exatas e 04 das ciências humanas. O tempo de serviço desses professores, na Universidade de São Paulo, oscila de 04 meses a 23 anos: sete docentes até 09 meses, dezoito de 01 a 05 anos, doze de 06 a 23 anos. Destaca-se que a maioria dos participantes tem menos de cinco anos de serviço na USP.

Os participantes da pesquisa foram consultados e assinaram o Termo de Consentimento Livre e Esclarecido, após a entrega dos textos produzidos. A pesquisa foi aprovada pelo Comitê de Ética da Escola de Enfermagem de Ribeirão Preto/USP, atendendo a Resolução CNS 196/96, vigente na época.

Os textos foram analisados na perspectiva da análise de conteúdo - modalidade análise temática, que consiste em apreender os núcleos 
de sentido que compõem uma comunicação cuja presença tenha algum significado para o objetivo analítico visado (BARDIN, 2010; MINAYO et al, 2010). Esta análise consiste em três etapas: pré-análise, exploração do material, tratamento dos resultados obtidos e interpretação.

No processo de análise, os núcleos de sentido foram construídos, reagrupados e interpretados a partir do referencial teórico adotado e dos sentidos e sutilezas que permearam os textos reflexivos produzidos pelos sujeitos. Foram constituídos como núcleos: processo de revisitação das práticas pedagógicas, limites contextuais e administrativos, gestão do projeto político pedagógico e possibilidades de mudanças nas práticas pedagógicas, explicitados na sequência.

\section{Processo de revisitação das práticas pedagógicas}

A formação profissional e práticas docentes no Brasil foram influenciadas, principalmente, pela pedagogia tecnicista (SAVIANI, 2009) na qual os conhecimentos e experiências são transmitidos aos estudantes, prioritariamente, pela concepção bancária de ensino (FREIRE, 1997), reproduzindo uma relação de sabedoria, de hierarquia e de poder tida como um dos dogmas da universidade. As reflexões realizadas pelos professores sobre sua ação docente evidenciam essa realidade:

[...] considero que minha aula expositiva seja acima da média. Esta consideração está embasada tanto na avaliação semestral feita pelos alunos, quanto em uma autocrítica pessoal [...] Entretanto, a participação dos alunos sempre foi aquém do que eu esperava. Esta constatação me fez começar a refletir sobre a ação docente e percebi que eu havia realizado uma escolha muito infeliz quando optei por deixar a licenciatura de lado [...] Existem diversas maneiras de se abordar conteúdos, sendo que a aula expositiva certamente representa a pior delas. Da mesma forma, existem diversas maneiras de se avaliar o aprendizado [...]" (P2 2009). 
[...] As teorias apresentadas me fizeram refletir sobre as minhas ações em sala de aula. Foi um bom feedback de que estou no caminho certo. Apesar de ainda ministrar aulas expositivas tradicionais, tenho inserido seminários, vídeos, sensibilização com apresentação de casos clínicos e visitas a locais fora da sala de aula, buscando a fixação na prática dos conteúdos teóricos previamente apresentados" (P12 2008).

Ao refletir sobre minha prática docente identifiquei que na sede de fornecer aos estudantes uma maior bagagem de conteúdo estava retornando a estratégias mais expositivas e com pouca participação ativa dos acadêmicos [...]" (P2 2008).

Muitos professores demonstram preocupação com questões de ordem metodológica, permeadas por uma série de padrões mentais, crenças e imagens relacionadas às experiências escolares prévias que vivenciaram como estudantes e que influenciam na forma como enfrentam a complexa tarefa de ensinar (VAILLANT; MARCELO, 2012):

O curso tem me feito refletir e buscar frequentemente não novas formas de ensinar, mas levar o aluno a aprender construindo seus conhecimentos, estimulando-o a querer conhecer, pesquisar, buscar informações [...] contextualização de cada conceito trabalhado [...] (P7 2008).

Tenho refletido que muitas vezes não temos clareza do processo ensino-aprendizagem dos estudantes. Isso interfere no processo de ensinar; ficamos aliviados por ter dado conta do programa, mas esse nem sempre é decodificado e aprendido pelos estudantes (P10 2008).

O processo de revisitação das práticas pedagógicas pressupõe a tomada de decisões, que envolve a relação professor-estudante, relação com o saber, aspectos comunicacionais e afetivos de grupo, além dos racionais, em um processo de formação de pessoas (CHARLOT, 2002). Existe uma tensão que faz parte do ato pedagógico tendo em vista que os professores não produzem diretamente seu trabalho, uma vez que os estudantes são protagonistas de sua própria atividade intelectual. 
O cotidiano em sala de aula vai mostrando-se desafiador na medida em que o professor entra em contato, durante o Curso de Pedagogia Universitária, com referenciais teórico-metodológicos específicos do campo da didática e pedagogia sendo, inclusive, verbalizado por alguns, que este campo de saber é novo para eles:

[...] Após o curso, encontrei-me em total desequilíbrio, pois já ansiava por dinamizar a forma de ensinar há algum tempo e não tinha o conhecimento [...] Agora tenho a plena consciência de que para ser uma professora completa [...] terei que por em prática os requisitos mínimos e as competências que ainda não consegui organizar e aplicar de forma adequada, satisfatória e contínua e que esses requisitos constituem o básico de uma aula dialógica [...] (P9 2008).

[...] Procuro alternativas de avaliação que não sejam centradas somente nas provas [...] compartilho resultados das pesquisas atuais sobre o assunto da aula que estou ministrando [...] inabilidade em aumentar a interatividade dos alunos talvez por falta de conhecimento pedagógico para tal (P14 2008).

Considerando que as reflexões sobre os métodos de ensino relacionam-se com concepções fundamentais sobre mundo, homem, relações sociais e educação, a construção de novas compreensões pelos professores demanda, dentre outros, tempo para estudo, reflexão individual e coletiva e busca de conhecimentos das ciências humanas que auxiliam a compor, de modo consistente e fundamentado, outro olhar para a realidade.

Ainda que o Curso de Pedagogia Universitária envolva uma proposta gradativa, desenvolvida no período de seis a dez meses, existe a possibilidade dos professores ficarem, em alguns momentos, na "superficialidade" de alguns conceitos, pois as oportunidades posteriores de continuidade dos estudos do campo pedagógico e de reflexão coletiva sobre as mudanças empreendidas em sala de aula muitas vezes são escassas. $\mathrm{Ou}$ seja, não faz parte do cotidiano dos professores, de modo geral, vivenciar processos de trabalho que tragam à tona a docência em perspectiva 
crítico-reflexiva e como trabalho coletivo. Construir mudanças no ensino depende de docentes inovadores, porém, esta é uma condição necessária, mas não suficiente. Toda inovação acarreta implicações institucionais como necessidade de recursos, apoio institucional e participação coletiva de professores (ZABALZA; CERDEIRIÑA, 2012).

O desafio que se coloca, para além da valorização dos fundamentos metodológicos da educação superior refletidos na grande maioria dos textos dos professores, não é apenas adotar uma metodologia problematizadora, dialética ou inovadora, mas compreender que a profissão docente incorpora as dimensões de cunho pessoal, profissional e institucional.

\section{Limites contextuais e administrativos}

Autores como Cunha (2014), Pimenta e Anastasiou (2011) e Cordeiro et al (2013) ressaltam que a docência universitária, diante da sociedade atual permeada pela globalização, multiculturalismo e virtualização, necessita transpor a barreira disciplinar. Tal compreensão aponta a necessidade do professor universitário ter formação aprofundada nos conteúdos de sua área de atuação, em investigação científica e nos saberes que envolvem o ofício de ensinar e as singularidades do seu exercício. No entanto, apesar dessa complexidade, de modo geral o professor universitário inicia seu trabalho desprovido de formação específica para a docência uma vez que os cursos de pós-graduação privilegiam a formação para a pesquisa. Esta situação pode ser visualizada em dois fragmentos:

Da noite para o dia me tornei docente sem ter acesso prévio às práticas pedagógicas (P6 2008).

As reflexões iniciais feitas já na abertura desse curso de PU sobre o quanto é frequente dormirmos profissionais e acordarmos como professores e o quanto é impossível dormirmos professores e acordarmos médicos, enfermeiros, psicólogos, etc. foi muito forte [...] (P15 2008). 
Zabalza (2007, p. 107) nos instiga a uma reflexão acerca da docência universitária na medida em que assinala que esta é "extremamente contraditória em relação a seus parâmetros de identidade socioprofissional", pois muitos professores reconhecem-se mais sob o âmbito científico (como médicos, engenheiros, matemáticos) do que como docentes universitários (como professor de...). Para o autor, essa situação denomina-se identidade profissional indefinida, pois sua prática profissional está orientada para o domínio científico e ou para o exercício das atividades vinculadas a ele. Contudo, quando o exercício da docência se apresenta como uma atividade profissional, o conhecimento científico refere-se à própria especialidade.

A desvalorização que as Universidades vêm atribuindo à docência, uma das dimensões primordiais da prática do professor universitário no contexto das políticas de avaliação docente, também está presente nos textos analisados:

Mudar o trabalho docente supõe a revisão de concepções e o desenvolvimento de competências inéditas que exigem esforço e dedicação extrema, tarefas bastante complexas se considerarmos o valor atribuído ao ensino dentre as muitas atribuições do professor universitário [...] é preciso valorizar o ensino de graduação e as experiências inovadoras na atividade docente, através da criação de mecanismos de incentivo, pessoais ou institucionais (P4 2008).

Falta um docente para a disciplina. Problema estrutural-administrativo é atribuído aos docentes da disciplina. Não entendo (P3 2008).

[...] é necessário o compromisso da instituição no que se refere à criação de políticas destinadas à capacitação e educação continuada do corpo docente como recurso humano de excelência (P3 2009).

No Brasil, assim como em alguns países europeus, evidencia-se a valorização da pesquisa em detrimento da docência, apesar da exigência da Universidade que se situa no âmbito do ensino, pesquisa e extensão, bem como as atividades de administração nos diversos setores institucionais. A dicotomia presente entre ensino e pesquisa é igualmente um fator de tensão 
que afeta o trabalho docente na Universidade, pois cobra-se dos professores a "produtividade" pela quantidade e qualidade de publicações, provocando preferência pela pesquisa em detrimento do ensino. $\mathrm{Na}$ verdade, a tríade ensino, pesquisa e extensão deveria ser entendida e colocada em prática de maneira articulada, contribuindo para a ressignificação da docência.

Alguns dos aspectos pontuados pelos professores referem-se à organização do trabalho docente, mais especificamente à dimensão administrativa do papel docente relacionada com as condições contratuais, os sistemas de seleção e promoção, as condições como carga horária, as obrigações vinculadas ao exercício profissional, dentre outras (ZABALZA, 2007).

Ressalta-se que poucos docentes expressaram em suas reflexões questões diretamente relacionadas à dimensão administrativa da docência, apesar de, em alguns momentos do curso, este tema ter sido abordado, inclusive com indicações de leituras críticas. Alguns professores, em suas reflexões, parecem conscientes quanto à complexidade do contexto e do processo de trabalho na universidade. Mas estariam eles sentindo-se impotentes e sem possibilidades de exercerem posicionamento crítico? Rendendo-se à lógica da produtividade em pesquisa "a qualquer custo" em detrimento de alguns valores? As práticas formativas dos professores estarão ainda mais instrumentalizadoras de um fazer pedagógico imediato do que promotoras da construção do pensar crítico reflexivo sobre a docência e desenvolvimento do compromisso social que ela representa? Enfim, conjecturas variadas, complexas, que colocam em foco a formação e a atuação política do docente universitário na atualidade.

\section{Gestão do Projeto político pedagógico e possibilidades de mudanças na prática pedagógica}

Parte dos relatos dos professores, principalmente dos gestores de curso, apontam que as aprendizagens relacionadas ao Projeto Político Pedagógico foram significativas para sua atuação junto aos cursos de graduação e possibilidades de fortalecimento do trabalho coletivo, 
evidenciando que mudanças mais efetivas extrapolam a atuação individual do professor em sala de aula. Esta visão representa um dos dilemas profissionais apontados por Zabalza (2007) como individualismo/ coordenação:

[...] é necessário que todos os atores envolvidos nesse trabalho executem harmonicamente sua parte [...] O curso de Pedagogia tem reforçado a necessidade de um trabalho junto a cada docente no sentido de conscientizá-lo do perfil do nosso egresso e da necessidade de construção desse perfil [...] (P7 2008).

Pretendo criar grupos de trabalho paralelos à $\mathrm{CoC}$ (Comissão de Coordenação de Curso), mas com o suporte técnico dela, visando motivar os colegas para a discussão dos conteúdos integrados por áreas afins e dos saberes necessários à formação [...] baseado no perfil profissiográfico [...] Todo este trabalho só será possível através de uma gestão integrativa e articulada de um colegiado ativo e participativo (P12 2008).

[...] Um avanço foi a realização de um workshop do curso [...] Outro avanço [...] foi a criação da CoC (Comissão Coordenadora) [...] já se iniciaram as discussões para tomar ações concretas na melhoria do curso [...] (P16 2008).

[...] No âmbito pedagógico não há como melhorar sem se envolver com os alunos (buscando compreender o que eles precisam), com os colegas (buscando as parcerias para as ações), com a instituição (entendendo o perfil de profissional que a universidade quer formar) (P1 2009).

[...] Uma das maiores mobilizações foi quanto ao conceito de planejamento, expressando-se em termos de processo de trabalho coletivo junto a meus alunos e a meus pares [...] (P3 2009).

O projeto pedagógico é compreendido como instrumento de gestão, o que implica em tocar na necessidade de construção cotidiana do trabalho coletivo, sendo esse mais um importante desafio para as coordenações de curso. Este desafio relaciona-se ao enfrentamento de se lidar 
com o predomínio do trabalho mais individualizado do docente universitário, bem como com as estruturas departamentais que acabam fragmentando o curso em disciplinas. Tais fatos atingem os docentes, pois estes perdem a visão de unidade que se tece pela interligação, diálogo e negociação dos saberes, das experiências, dos sujeitos em suas intencionalidades na construção do curso.

As questões relacionadas ao currículo, apontadas nos relatos abaixo, corroboram com a gestão das Comissões Coordenadoras de Curso $(\mathrm{CoCs})$ no que diz respeito à implementação do $\mathrm{PPP}$ e os decorrentes processos avaliativos:

Acredito que o curso [Pedagogia Universitária] também tem ajudado minha inserção nas discussões administrativas do curso [...] como participante ativa desse processo, principalmente agora na discussão do PPP e da possibilidade de mudança na distribuição das disciplinas em grade para uma matriz curricular (P11 2008).

[...] Redefinição do texto do projeto político pedagógico, desenvolvimentos de novos modelos de avaliação do curso e ao longo do tempo um amadurecimento sobre possíveis mudanças na estrutura curricular (P12 2008).

A integração entre as disciplinas é um problema a ser atacado de imediato, pois várias disciplinas estão sendo ministradas sem o devido cuidado de relacioná-las com os conteúdos anteriores e posteriores do curso (P2 2009).

A ruptura de paradigmas envolve incertezas e o conhecimento fragmentado parece enraizado na prática docente e na estrutura curricular do curso (grade e disciplinas) que engessa articulações. Apesar das Diretrizes Curriculares dos Cursos de Graduação apontarem claramente para a importância da articulação teoria-prática, da flexibilização curricular e da matriz integrativa, muitos cursos agarram-se a um modelo de currículo que não condiz com as descobertas mais recentes da própria ciência (P3 2009). 
Na elaboração/implementação do projeto pedagógico, segundo Veiga (2008) há que se considerar alguns aspectos: que ele seja construído a partir da própria realidade, analisando os problemas existentes e as situações nas quais aparecem; que seja exequível, sendo previstas as condições necessárias ao seu desenvolvimento e avaliação; que ele se construa e se implemente por ação articulada entre todos os envolvidos com a realidade da sala de aula, sendo construído continuamente, pois ao mesmo tempo é produto e processo.

Os relatos dos professores mostram apropriação de conceitos que podem fundamentar ações transformadoras nos cursos de graduação, todavia, devem ser considerados os limites que podem ser encontrados no atual contexto da universidade, como as dificuldades em articular as distintas instâncias de poder que estão implicadas nas decisões acerca do ensino de graduação nas unidades de ensino, principalmente nos departamentos; pouco reconhecimento da importância das coordenações pelas instâncias acadêmicas; ausência de representação das coordenações junto aos órgãos colegiados superiores, conflitos políticos e administrativos no que diz respeito às questões pedagógicas. Essas dificuldades não são estranhas ao contexto e, provavelmente, enfrentá-las, redimensioná-las e superá-las, na construção de outras relações, será imprescindível para o trabalho das CoCs (CORRÊA et al., 2011).

\section{Considerações finais}

As reflexões realizadas pelos professores apontam para um quadro de pressões e demandas postas à universidade, decorrentes das transformações socioeconômicas e culturais. É importante salientar para os limites intrínsecos de um programa de formação pedagógica, que "por si só não é suficiente para responder com qualidade à superação das fragilidades oriundas da formação pedagógica de docentes" (VEIGA, 2012, p. 12). Entretanto, admite-se a importância desses Programas no que concerne à apreensão dos cenários institucionalizados de formação e sua contribuição 
para o desenvolvimento profissional docente nos campos teórico-metodológico, dinâmicas organizacionais e atuação pedagógico-didática.

Evidencia-se na análise do processo de revisitação das práticas pedagógicas dos docentes investigados uma tensão entre a prática institucionalizada acerca da metodologia de ensino em uma perspectiva bancária e outras formas que protagonizem os estudantes, como sujeitos partícipes em seu processo de aprendizagem. Não há técnicas por si só inteiramente bem sucedidas e, muitas vezes, não há consenso profissional em muitas áreas de ação, quer em relação aos meios, quer em relação aos próprios fins. Estes dissensos profissionais resultam de diferentes opções teóricas presentes em qualquer área do saber, mas também, mais do que noutras áreas, com diferenças significativas de crenças, valores e ideologias.

No que diz respeito aos limites contextuais e administrativos e gestão do Projeto Pedagógico, os dados revelam que os docentes assinalam como um dos focos de tensão a indissociabilidade do ensino, pesquisa e extensão, considerando-se o lugar que a Universidade ocupa na sociedade atual com suas demandas e prioridades. Mas, acenam como possibilidades a ressignificação do ensino de graduação na perspectiva da formação e compromisso social, a compreensão do Projeto Pedagógico como instrumento de gestão, de formação profissional e trabalho coletivo.

Assim sendo, reafirma-se o conceito de profissionalização docente no âmbito de um conceito de profissão social, complexo e multidimensional, que não se resume à formação profissional, mas envolve alternativas que possibilitam melhorar as condições objetivas de trabalho, atuação e que respeitem as práticas pedagógicas construídas ao longo da experiência profissional. Acrescentam-se a esse cenário, questões macroestruturais, consubstanciadas nas alterações no mundo do trabalho e da produção, especificidade e complexidade da educação superior no Brasil com seus diferentes processos de trabalho, gestão, regime de trabalho, salário, ordenamentos legais e institucionais que se apresentam como um amálgama neste nível de ensino. 
O estudo sinaliza que a profissionalização docente tem implicações com o desenvolvimento de relações pedagógicas no âmbito da sala de aula, desenvolvimento do currículo articulado e contextualizado, compromisso ético-político na vivência das diversas práticas socioculturais, em particular, no exercício da docência, assumindo uma postura profissional consoante com a profissão professor. No entanto, visualizam-se pontos de tensão que precisam ser compreendidos e trabalhados: aprendizagem da docência como fenômeno individual e aprendizagem da docência como fenômeno coletivo; formação pedagógica como prática sócio-política e formação como prática instrumental; tensão entre ensino e pesquisa; hierarquização de saberes e os desafios para fortalecer as políticas e ações de formação político-pedagógica do professor universitário. As pontuações dos professores registradas nessa investigação podem ser reveladoras de que processos formativos, como os vividos no curso pedagogia universitária, despertam inquietações, mobilizadoras de um movimento reflexivo que traz à tona a compreensão e a busca de alternativas para a docência no ensino superior.

\section{Referências}

ALMEIDA, M. I.; PIMENTA, S. G. A construção da pedagogia universitária no âmbito da Universidade de São Paulo. In: PIMENTA, S. G.; ALMEIDA, M. I. (Orgs). Pedagogia Universitária. São Paulo: Cortez, 2011. p. 19-43.

ALMEIDA, M. I. Formação do professor do Ensino Superior. 1 ${ }^{a}$. ed. São Paulo: Cortez, 2012.

BARDIN, L. Análise de conteúdo. Lisboa: Edições 70, 2010.

BRASIL. Lei no 9.394, de 20 de dezembro de 1996. Lei de Diretrizes e Bases da Educação Nacional. Diário Oficial da União, Brasília, DF, 23 dez. 1996. Seção 1, p. 27833. 
CHARLOT, B. Formação de professores: a pesquisa e a política educacional. In: PIMENTA, S. G.; GHEDIN, E. (Orgs.). Professor reflexivo no Brasil: gênese e crítica de um conceito. São Paulo: Cortez, 2002. p. 89-108.

CHAUÍ, M. A universidade pública sob nova perspectiva. Revista Brasileira de Educação. n. 24, p. 5-15, set./dez 2003.

CORDEIRO, T. de S. C et al. Desenvolvimento profissional docente na universidade: formação continuada didático-pedagógica como objeto de investigação, reflexão e intervenção. In: RAMOS, K. M. C; VEIGA, I. A. P.(Orgs). Desenvolvimento profissional docente: currículo, docência e avaliação na educação superior. Recife: Editora Universitária-UFPE, 2013, p. 21- 38.

CORRÊA, A. K. et al. Formação Pedagógica do professor universitário: reflexões a partir de uma experiência. In: PIMENTA, S. G.; ALMEIDA, M. I. (Orgs.). Pedagogia Universitária: caminhos para a formação de professores. $1^{\mathrm{a} e d}$. São Paulo: Cortez, 2011. v. 1, p. 75-100.

CUNHA, M. I.; BROILO, C. L.(Orgs.) Qualidade da Educação Superior: grupos investigativos internacionais em diálogo. Araraquara: Junqueira\&Marin, 2012.

CUNHA, M. I. (Org.) Estratégias institucionais para o desenvolvimento profissional docente e as assessorias pedagógicas universitárias: memórias, experiências, desafios e possibilidades. Araraquara: Junqueira\&Marin, 2014.

FREIRE, P. Papel da educação na humanização. Revista da Faculdade de Educação do Estado da Bahia, v. 6, n. 7, p. 9-32, 1997.

MARCELO GARCIA, C. A identidade docente: constantes desafios. Revista brasileira de Pesquisa sobre formação docente, v. 1, n. 1, p. 109-131, ago./dez. 2009.

MINAYO, M. C. S. et al (Org.) Pesquisa social: teoria, método e criatividade. $29^{a}$ ed. Petrópolis: Vozes, 2010.

NÓVOA, A. Professores: imagens do presente futuro. Lisboa: Educa, 2009.

PIMENTA, S. G.; ANASTASIOU, L. G. C. Docência no ensino superior. $5^{\mathrm{a}}$ ed. São Paulo: Cortez, 2011. 
SAVIANI, D. Escola e Democracia. 41ª ed. Campinas: Autores Associados, 2009. SGUISSARDI, V. A Universidade neoprofissional, heterônoma e competitiva. In: MANCEBO, D.; FÁVERO, M. L. A. (Orgs.). Universidade: políticas, avaliação e trabalho docente. $1^{\text {a }}$ ed. São Paulo: Cortez, 2004. p. 33-52.

SGUISSARDI, V. Universidade brasileira no século XXI: Desafios do presente. $1^{\mathrm{a}} \mathrm{ed}$. São Paulo: Cortez, 2009.

VAILLANT, D; MARCELO, C. Ensinando a Ensinar: As quatro etapas de uma aprendizagem. Curitiba: Ed. UTFPR, 2012.

VEIGA, I. P. A. Docência como atividade profissional. In: VEIGA, I. P. A.; D’ÁVILA, C. (Orgs). Profissão Docente: Novos sentidos, novas perspectivas. Campinas: Papirus, 2008. p. 13-21.

VEIGA, I. P. A. Universidade e desenvolvimento profissional docente: propostas em debate. Araraquara: Junqueira\&Marin, 2012.

ZABALZA, M. A. O ensino universitário: seu cenário e seus protagonistas. $2^{\mathrm{a}}$ ed. Porto Alegre: Artmed, 2007.

ZABALZA, M. A.; CERDEIRIÑA, M. A. Z. Planificación de la docencia en la universidad: Elaboración de las Guías Docentes de las materias. Madri: Narcea, 2012.

Recebido: 20/08/2016

Received: 08/20/2016

Aprovado: 13/05/2017

Approved: 05/13/2017 